\title{
PARAMETRIC STUDY OF LIGHT GAUGE STEEL LIPPED CHANNEL COLUMN SECTION
}

\author{
P. B. Patil ${ }^{1}$, P. D. Kumbhar ${ }^{2}$ \\ ${ }^{1}$ P. G. Student, Department of civil engineering, Rajarambapu Institute of Technology, Islampur, Maharashtra, India. \\ ${ }^{2}$ Associate Professor, Department of civil engineering, Rajarambapu Institute of Technology, Islampur, Maharashtra, \\ India.
}

\begin{abstract}
Light gauge steel lipped channel sections are being used popularly in shops, factories, automobile engineering and industries on account of their high strength to width ratio, simplicity in construction, flexibility in fabrication and high structural efficiency. A lot of research work has been carried out to study the structural behavior of axially loaded light gauge steel lipped column sections considering different parameters. However, structural behavior of light gauge steel lipped channel sections under eccentric loading has not received much attention.

The present paper focuses on the experimental study of structural behavior of light gauge steel lipped channel sections under eccentric loading by varying loading position in between center of gravity and shear center of channel column section. Finite element analysis of the section is also done using Abaqus software for different positions of the load. The results indicate that, load carrying capacity of the section increases as the loading position shifts towards supported edge of the section. The failure of the section occurs in the form of local-distortional buckling approximately between 1/3 ${ }^{\text {rd }}-1 / 2$ of the height of column. Results obtained by software are found to be in good agreement with experimental results.
\end{abstract}

Keywords - Light Gauge Lipped Channel Column, Structural Behavior, Local Buckling, Finite Element Analysis, Abaqus etc

\section{INTRODUCTION}

Thin sheet steel products are extensively used in all aspects of modern life; in the shop, factory, automobile engineering and industry. These thin steel sections with thickness between $1 \mathrm{~mm}$ to $8 \mathrm{~mm}$ are cold-formed, i.e. their manufacturing process involves forming steel sections in a cold state from steel sheets of uniform thickness. Such sections also known as Light Gauge Steel Sections (LGSS).The advantages of using LGS sections are high strength-to-weight ratio, easy for construction and flexibility in fabricating different cross section shapes. Cold-formed steel sections usually manufactured into hat sections, channel sections, Z-sections by cold-rolling or brakepressing technique. Light Gauge Steel Lipped Channel Columns (LGSLCC) are highly susceptible to instability phenomena such as local, distortional and global (flexural or flexural torsional) buckling. Depending on the column geometry (cross section and length) and end support conditions, its post-buckling behavior and ultimate strength may be significantly affected by interactions involving various buckling modes.

Local buckling mode of LGS sections depends, on its i) cross section geometry (shape $\&$ dimensions) and ii) and support conditions. In this mode compression buckles out weaker principle axis \& collapses occur at rate following excessive buckling deformation (no twisting). Normally, long columns undergo flexural buckling along half wave lengths. Due to smaller thickness of light gauge channel section have low torsional stiffness and Centre of Gravity (CG) does not coincide with Shear Center (SC), section will undergo flexural - torsional buckling.

As the LGSLCC section is asymmetrical, its maximum load carrying capacity is for the position of loads between CG and the SC of section. Therefore, in the present study the maximum load carrying capacity of the LGSLCC has been determined by varying the loading positions between CG and SC of the section. Also, the study has been carried out by applying load at the position, giving maximum load carrying capacity, for different slenderness ratios of the column section.

\section{EXPERIMENTAL STUDY}

The experimental study has been carried out considering LGSLCC of 60x60x15x2 mm size (Fig.1). IS 801:1975 provides $5.99 \mathrm{~cm}$ as the distance between CG and SC for section under consideration. To determine proper location of loading for maximum load carrying capacity, point load applied between center of gravity and shear center at each $2 \mathrm{~cm}$ interval on selected channel section with $700 \mathrm{~mm}$ length. With known proper location of load, effect of slenderness ratio was studied with column section of $700 \mathrm{~mm}, 800 \mathrm{~mm}$ and $900 \mathrm{~mm}$ length. The properties of LGSLCC section is shown in fig. 1. 


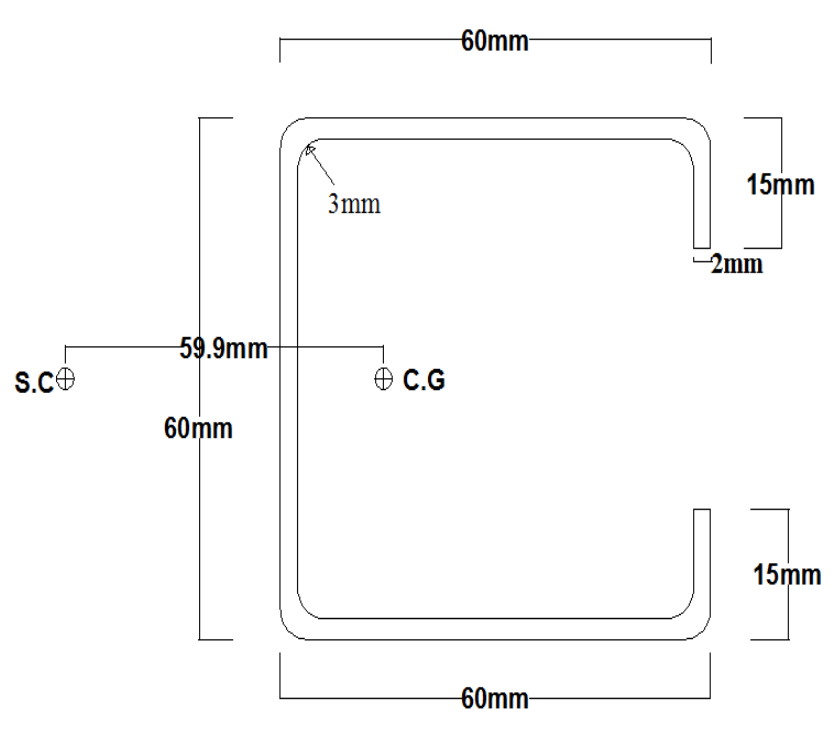

Fig.1 Details of LGSLCC section

\subsection{Preparation of Test Specimens}

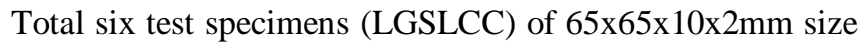
and of heights $700 \mathrm{~mm}, 800 \mathrm{~mm}$ and $900 \mathrm{~mm}$, fabricated were used for the experimentation. Four column specimens of length $700 \mathrm{~mm}$ are fabricated with eccentricity at zero (axially loaded), $2 \mathrm{~cm}, 4 \mathrm{~cm}$ and $5.99 \mathrm{~cm}$ distance and two column specimens of length $800 \mathrm{~mm}$ and $900 \mathrm{~mm}$ are fabricated with $2 \mathrm{~cm}$ eccentricity. The specimens were provided with a $12 \mathrm{~mm}$ thick steel plate of $150 \mathrm{~mm} \times 150 \mathrm{~mm}$ size at both, top and bottom, ends of the column. Details of test specimens prepared with different eccentricity are shown in fig. 2 .

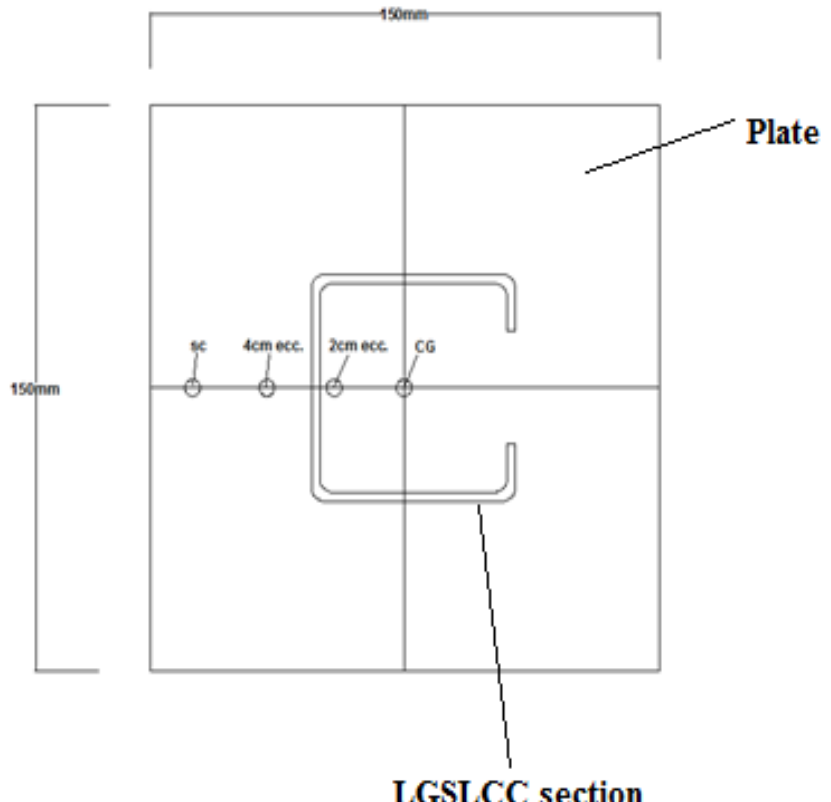

Fig.2 Details of LGSLCC section with different eccentricity

The top end of the specimen was provided with an arrangement so as to have hinged support was provided at the top while fixed support was provided at bottom end of the column section. To apply point load at the top of the column, the groove of diameter $25 \mathrm{~mm}$ is provided to the top plate (fig. 2 a). The test setup and end conditions provided during experiments are shown in fig.3 (a), (b), and (c).

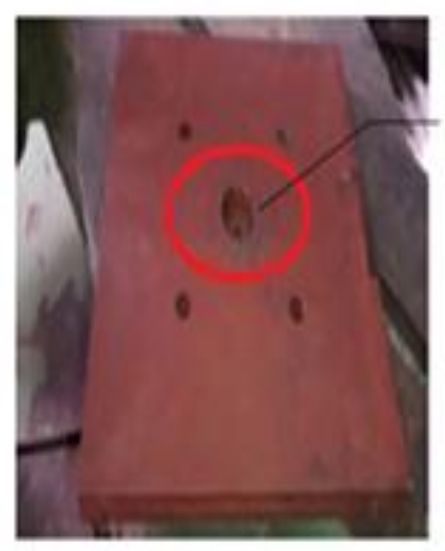

\section{$25 \mathrm{~mm}$ dia. groove}

Fig.3 (a) $25 \mathrm{~mm}$ dia. Groove on plate

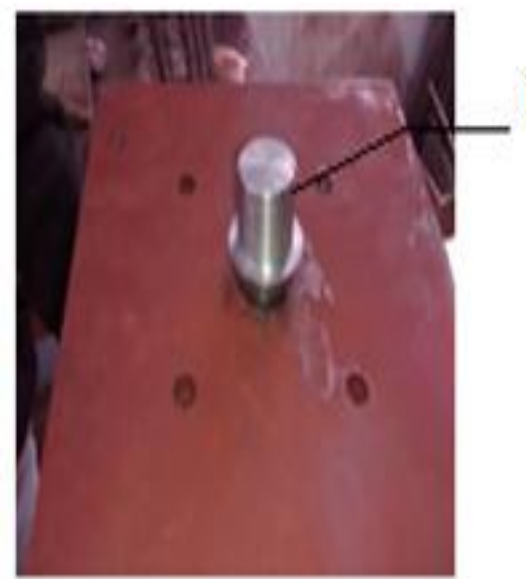

Hinge condition

Fig.3 (b) Setup for hinge end

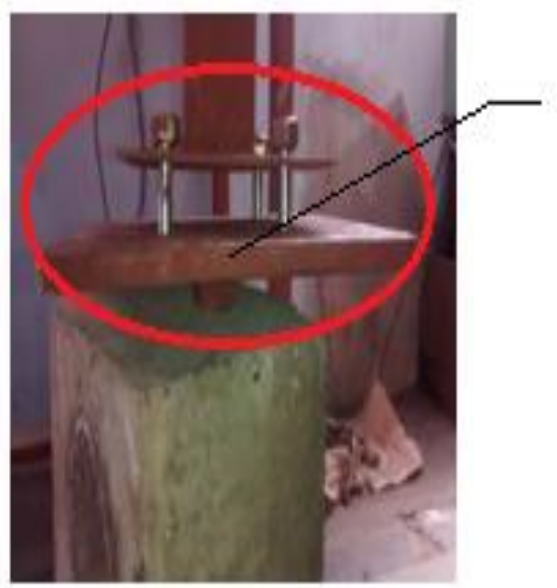

Fixed condition

Fig.3 (c) Setup for fixed end

\subsection{Testing under Axial and Eccentric Loading}

In fig.4, details of test setup provided during experiment are shown. To measure deflection of flange and web of LGSLCC section dial gauge and LVDT are provided respectively. 

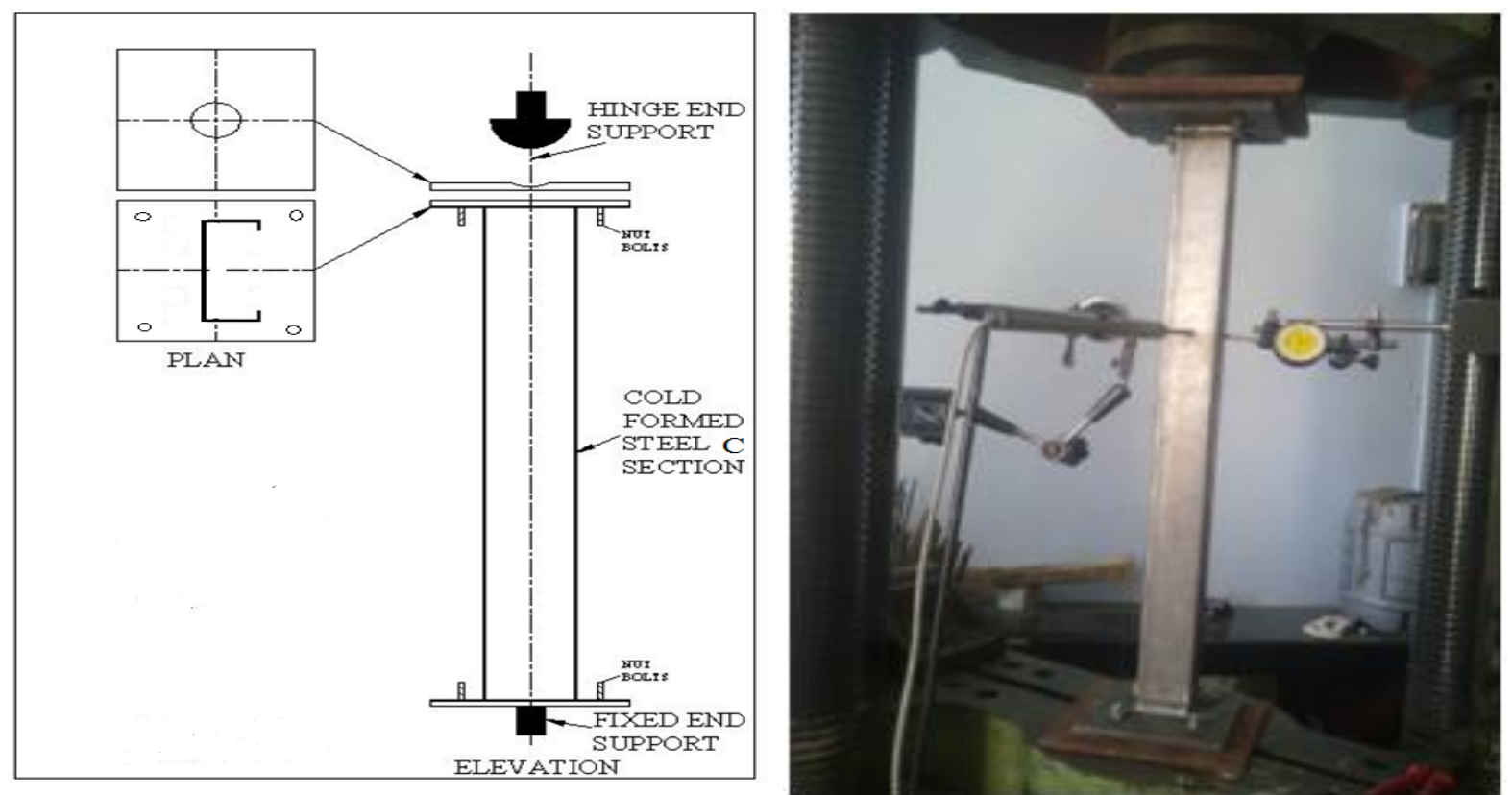

Fig.4 Detail of test setup

\subsection{Finite Element Analysis of Lipped Channel}

\section{Column Section}

The finite element analysis of light gauge steel lipped channel column section has done by using finite element analysis software ABAQUS version 6.10-1. The channels were modeled using shell element S4R. The columns were analyzed for hinged-fixed boundary condition. Tetrahedron mesh type has used for meshing of model. Elastic modulus $(E)=2.0 \times 10^{5} \mathrm{~N} / \mathrm{mm}^{2}$ and Poisson ratio $(\mu)=0.3$ were used as material properties. Tetrahedron mesh type has used for meshing of element. The fig. 5 (a), (b), (c) and (d) shows steps have been used for finite element analysis by using Abaqus software.

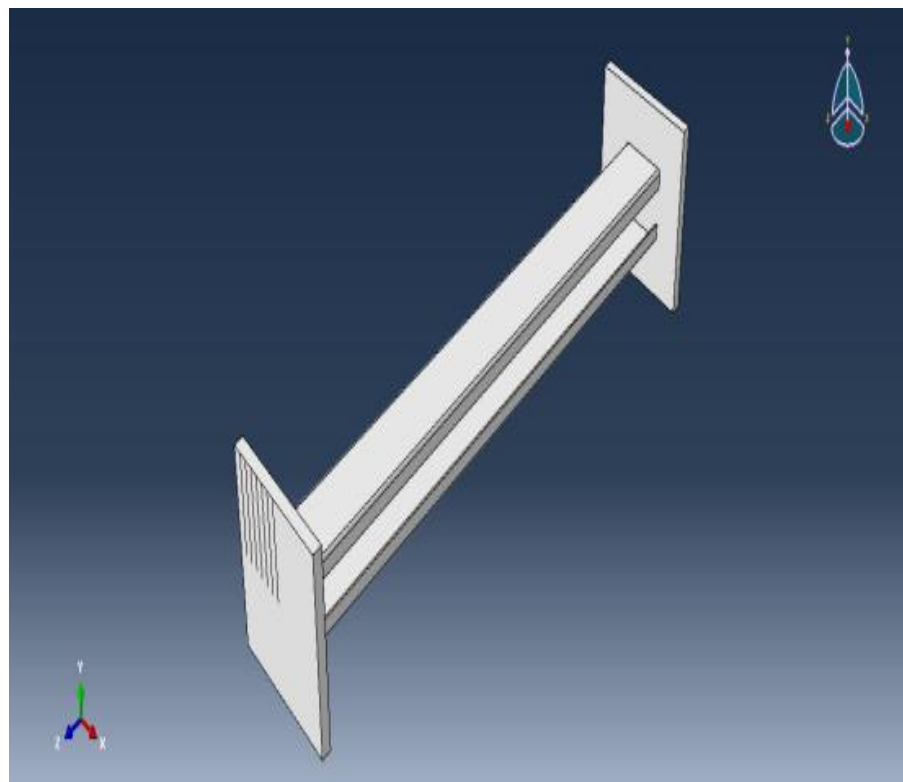

Fig.5 (a) Modeling of channel column

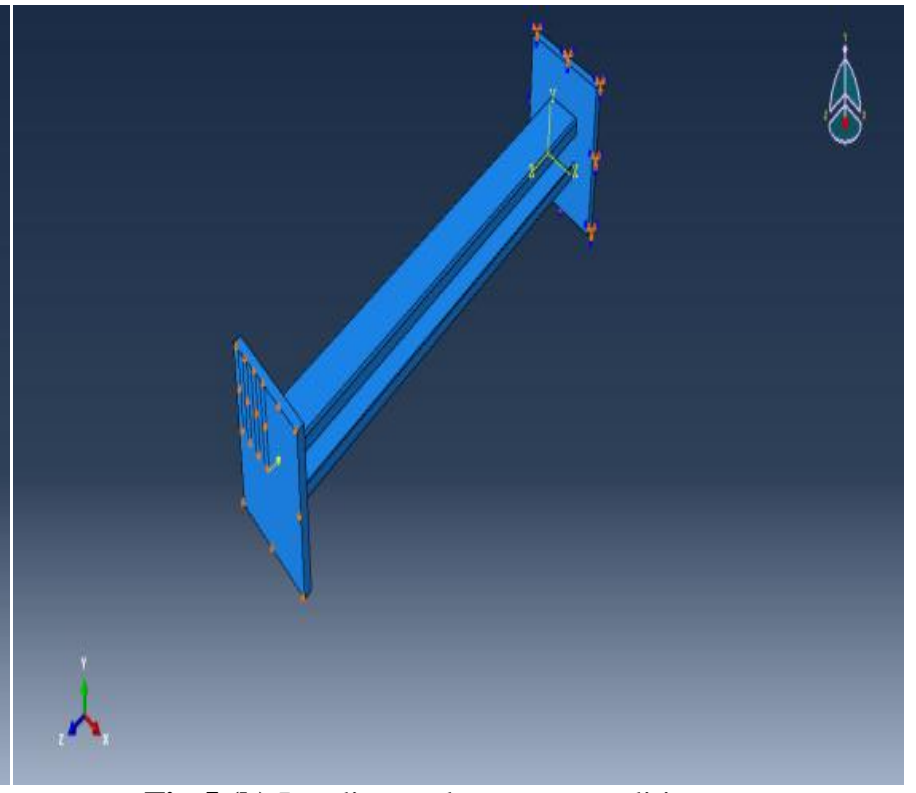

Fig.5 (b) Loading and support condition 


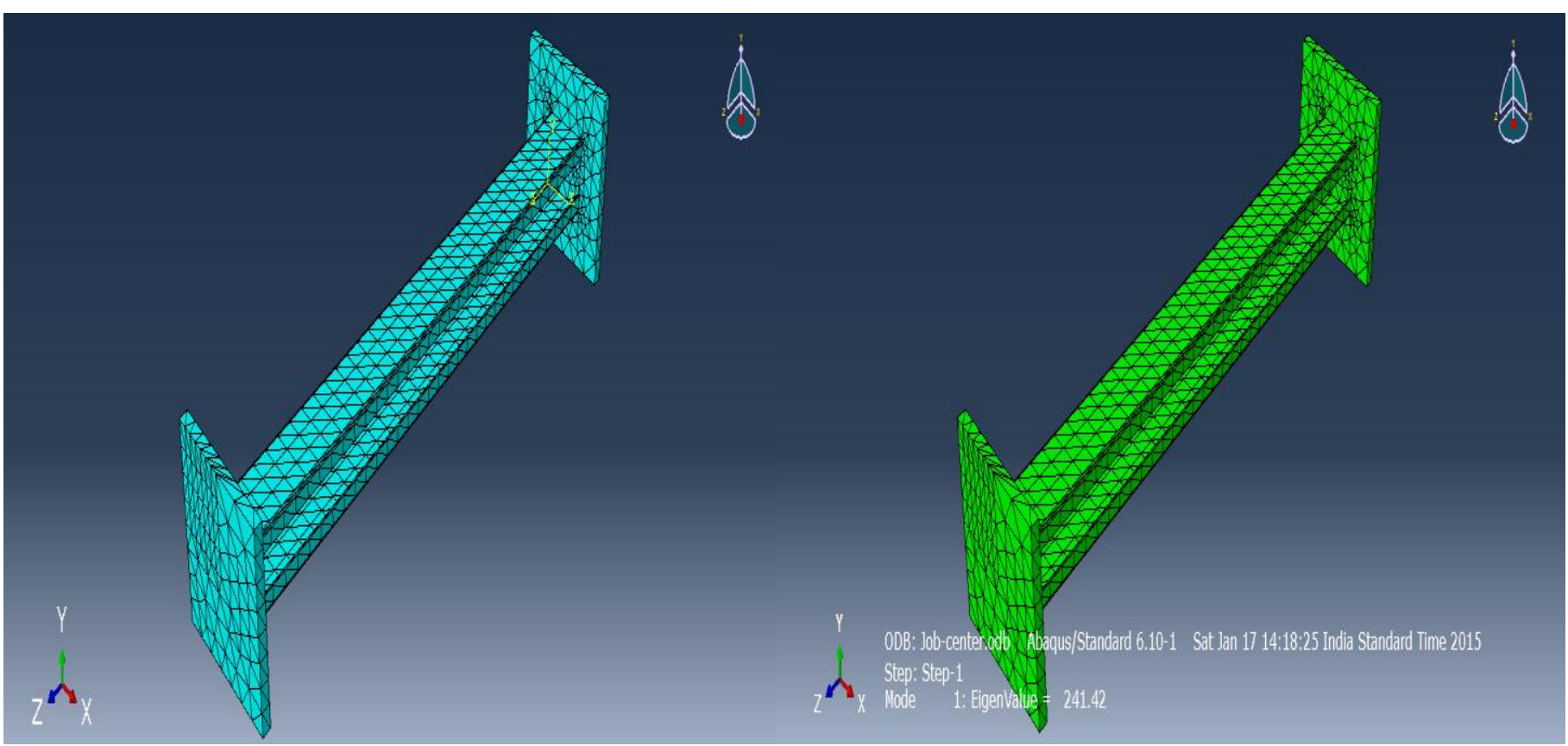

Fig.5 (c) Meshing of model

Fig.5 (d) Result of analysis

\section{RESULTS AND DISCUSSION}

The results obtained by experiments and finite element analysis software ABAQUS are compared below

\subsection{Load Carrying Capacity of Light Gauge Steel}

\section{Lipped Channel Column Section with different}

\section{Loading Position}

The ultimate load of LGSLCC section with different eccentricity has obtained by experiments and Abaqus software is tabulated in table 1.

Table 1 Load position and ultimate load of channel column section by experiment and ABAQUS software

\begin{tabular}{|c|c|c|c|c|c|}
\hline \multirow{2}{*}{$\begin{array}{l}\text { Sr. } \\
\text { No } \\
\text {. }\end{array}$} & \multirow{2}{*}{$\begin{array}{l}\text { Sectio } \\
\text { n }\end{array}$} & \multirow{2}{*}{$\begin{array}{l}\text { Load } \\
\text { positio } \\
\text { n }\end{array}$} & \multicolumn{2}{|c|}{ Ultimate load (KN) } & \multirow{2}{*}{$\begin{array}{l}\text { Erro } \\
\mathbf{r} \\
(\%)\end{array}$} \\
\hline & & & $\begin{array}{l}\text { Experimenta } \\
\text { I results }\end{array}$ & $\begin{array}{l}\text { Abaqu } \\
\text { s } \\
\text { results }\end{array}$ & \\
\hline 1 & 1 & At C.G & 90 & 93.189 & 3.42 \\
\hline 2 & 2 & $2 \mathrm{~cm}$ & 92.50 & 94.530 & 2.14 \\
\hline 3 & 3 & $4 \mathrm{~cm}$ & 72.50 & 74.492 & 2.67 \\
\hline 4 & 4 & $\begin{array}{l}\text { At } \\
\text { shear } \\
\text { center } \\
(5.99 \\
\mathrm{cm})\end{array}$ & 40.50 & 42.237 & 4.11 \\
\hline
\end{tabular}

The ultimate load at $2 \mathrm{~cm}$ from center of gravity of channel section is $92.50 \mathrm{KN}$ by experiment. Therefore, the proper load position of the channel section for maximum load carrying capacity is $2 \mathrm{~cm}$ from the shear center.

\subsection{Effect of Varying Slenderness Ratio on Load}

Carrying Capacity of Light Gauge Steel Lipped

\section{Channel Column Section}

To study effect of varying slenderness ratio on load carrying capacity of lipped channel column section test were carried out on LGSLCC sections of length $700 \mathrm{~mm}$ to $900 \mathrm{~mm}$ with eccentricity $2 \mathrm{~cm}$. The results obtained by experiments and ABAQUS software are tabulated in table 2.

Table 2 Slenderness ratio and ultimate load of channel column section by experiment and ABAQUS software

\begin{tabular}{|c|c|c|c|c|c|}
\hline \multirow{2}{*}{$\begin{array}{l}\text { Sr. } \\
\text { No } \\
\text {. }\end{array}$} & \multirow{2}{*}{$\begin{array}{l}\text { Sectio } \\
\text { n }\end{array}$} & \multirow{2}{*}{$\begin{array}{l}\text { Length } \\
\text { of } \\
\text { colum } \\
\text { n } \\
(\mathrm{mm})\end{array}$} & \multicolumn{2}{|c|}{ Ultimate load (KN) } & \multirow{2}{*}{$\begin{array}{l}\text { Erro } \\
\mathbf{r} \\
(\%)\end{array}$} \\
\hline & & & $\begin{array}{l}\text { Experimenta } \\
\text { l results }\end{array}$ & $\begin{array}{l}\text { Abaqu } \\
\text { s } \\
\text { results }\end{array}$ & \\
\hline 1 & 2 & 700 & 92.50 & 94.530 & 2.14 \\
\hline 2 & 5 & 800 & 57.00 & 59.420 & 4.07 \\
\hline 3 & 6 & 900 & 50.50 & 51.813 & 2.53 \\
\hline
\end{tabular}




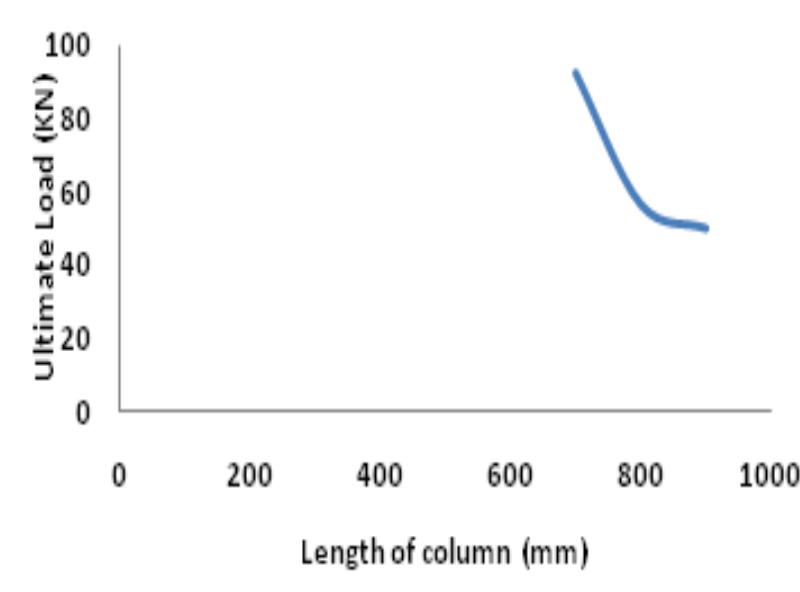

As increase in the slenderness ratio load carrying capacity decreases from $92.50 \mathrm{KN}$ to $50.50 \mathrm{KN}$.

\subsection{Failure Pattern of Light Gauge Steel Lipped Channel Column Section during Testing}

All sections failed by local-distortional buckling, shown by LGSLCC section during experiment and by Abaqus software is shown in fig.7.

Fig.6 Graph of Length of column v/s ultimate load of channel section

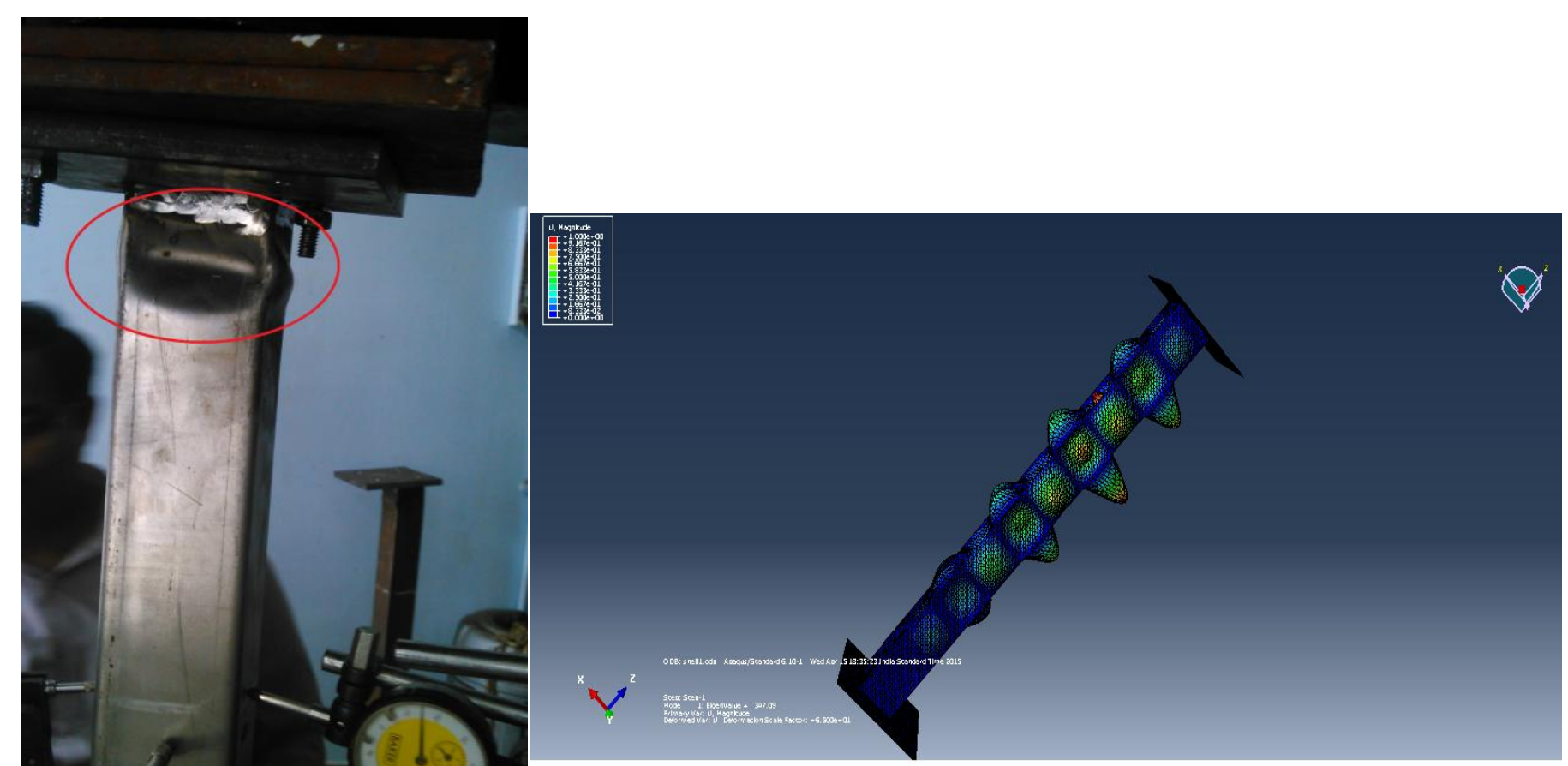

Fig. 7 Failure pattern of light gauge steel lipped channel column sections by experiment and using Abaqus software

\section{CONCLUSION}

In the present work load position is find out for maximum load carrying capacity of channel section $(60 \times 60 \times 15 \times 2) \mathrm{mm}$ with varying the load position between center of gravity and shear center of the section. With known load position for maximum load carrying capacity of section effect of slenderness ratio is studied. From the study it is concluded that,

1. The ultimate load increases as the position of load moves towards the supported edge of the channel section.

2. Light gauge channel column sections are subjected to local, distortional failure due to its smaller thickness.

3. With increase in slenderness ratio load carrying capacity of channel section is decreases.

4. Failure of all columns occurred at $1 / 3^{\text {rd }}$ to $1 / 2$ distance of column length.

\section{REFERENCES}

[1]. Young Bong kwon, Bong Sun Kim, Gregory J. Hancock (2009), "Compression Tests of High Strength Cold- Formed Steel Channels with Buckling Interaction", Journal of Construction Steel Research 65, 278 - 289.

[2]. M. Meiyalagan, M. Anbarasu and Dr. S. S. Sukumar (2010), "Investigation on Cold Formed C - Section Long Column with Intermediate Stiffener and Corner Lips Under Axial Compression", International Journal of Applied Engineering Research, Vol. 1, No. 1.

[3]. Shreedhar Kalavagunta, Sivakumar Naganathan and Kamal Nasharuddin Bin Mustapha (2010), "Experimental Study of Axially Compressed Cold Formed Steel Channel Columns", Indian Journal of Science and Technology. 
[4]. M. P. Kultunga, M. Macdonald, D. K. Harrison (2013), "Finite Element Analysis of Cold Formed Steel Structural Members with Perforations Subjected to Compression Loading", Mechanics and Mechanical Engineering, vol.17, No. 2, 127-139.

[5]. Shan-shan Cheng, Boksun Kim, Long-yuan Li (2013), "Lateral-Torsional Buckling of Cold-Formed channel Sections Subjected to Combined Compression and Bending", Journal of Constructional Steel Research 80, 174180.

[6]. Vijayasimhan M., Marimuthu V., Palani G. S. and Rama Mohan Rao P. (2013), " Comparative Study on Distortional Buckling Strength of Cold Formed Steel Lipped Channel Sections", Research Journal Engineering Science, Vol. 2(4), $10-15$.

[7]. Ziqi He, Xuhong Zhou, Zhanke Liu, Ming Chen (2014), "Post-Buckling Behaviour and DSM Design of WebStiffened Lipped Channel Columns with Distortional and Local Mode Interaction", Thin - Walled Structures 84, 189 $-203$.

[8]. Shreedhar Kalavanguta, Sivakumar Naganathan and Kamal Nasharuddin Bin Mustpha, "Experimental Study of Axially Compressed Cold Formed Steel Channel Columns", Indian Journal of Science and Technology. 